\title{
Language and Education
}

\section{Talking about talk: tutor and student expectations of oracy skills in higher education}

\author{
Marion Heron, Doris Dippold, Anesa Hosein, Ameena Khan Sullivan, Tijen \\ Aksit, Necmi Aksit, Jill Doubleday \& Kara McKeown
}

To cite this article: Marion Heron, Doris Dippold, Anesa Hosein, Ameena Khan Sullivan, Tijen Aksit, Necmi Aksit, Jill Doubleday \& Kara McKeown (2021) Talking about talk: tutor and student expectations of oracy skills in higher education, Language and Education, 35:4, 285-300, DOI: 10.1080/09500782.2021.1895206

To link to this article: https://doi.org/10.1080/09500782.2021.1895206

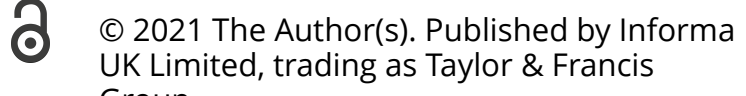
Group

曲 Published online: 23 Mar 2021.

Submit your article to this journal $\pi$

Lll Article views: 1019

Q View related articles $\widetilde{ }$

View Crossmark data $\nearrow$ 


\title{
Talking about talk: tutor and student expectations of oracy skills in higher education
}

\author{
Marion Heron ${ }^{\mathrm{a}}$ (D), Doris Dippold ${ }^{\mathrm{b}}$ (D), Anesa Hosein ${ }^{\mathrm{a}}$ (D), Ameena Khan Sullivan ${ }^{\mathrm{c}}$, \\ Tijen Aksit $^{d}$ (D), Necmi Aksit ${ }^{\mathrm{B}}$ (D), Jill Doubleday ${ }^{\mathrm{D}}$ (D) and Kara McKeown ${ }^{\mathrm{g}}$ (D)
}

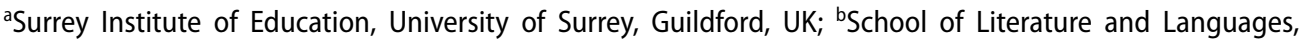
University of Surrey, Guildford, UK; 'Department of Applied Linguistics and Communication, Birkbeck College, University of London, UK; ${ }^{\mathrm{d} F a c u l t y}$ of Academic English, Bilkent University, Ankara, Turkey; ${ }^{\mathrm{e}}$ Graduate School of Education, Bilkent University, Ankara, Turkey; ${ }^{f}$ Academic Centre for International Students, University of Southampton, Southampton, UK; '9Academic Bridge Programme, Zayed University, Dubai, UAE

\begin{abstract}
Although participation in academic speaking events is a key to developing disciplinary understanding, students for whom English is a second language may have limited access to these learning events due to an increasingly dialogic and active higher education pedagogy which places considerable demands on their oracy skills. Drawing on the Oracy Skills Framework we explore disciplinary tutors' and students' expectations of oracy skills required for disciplinary study. An analysis of both quantitative and qualitative data found that disciplinary tutors placed importance on the cognitive dimension of oracy skills such as argumentation and asking questions, whilst students placed importance on linguistic accuracy. The findings also suggest that tutors and students lack a shared metalanguage to talk about oracy skills. We argue that a divergence of expectations and lack of shared terminology can result in compromising students' access to valuable classroom dialogue. The paper concludes with a number of practical suggestions through which both tutors and students can increase their understanding of oracy skills.
\end{abstract}

\section{ARTICLE HISTORY}

Received 21 August 2020

Accepted 20 February

2021

\section{KEYWORDS}

Oracy skills; ESL students; disciplinary studies; metalanguage; higher education

\section{Introduction}

Approaches to pedagogy in higher education are changing rapidly from a monologic approach to a more interactive, dialogic approach (Heron 2019). A focus on oracy is timely as academic speaking plays a role in negotiation of meaning in learning (Mauranen 2012) as well as demonstrating understanding of the discipline (Arkoudis and Doughney 2014). In a dialogic classroom, speaking activities can become 'high stakes' and students may be reluctant to participate for a number of sociocultural and linguistic reasons (Engin 2017; Mack 2012).

CONTACT Marion Heron m.heron@surrey.ac.uk Department of Higher Education, University of Surrey, Guildford, UK (c) 2021 The Author(s). Published by Informa UK Limited, trading as Taylor \& Francis Group

This is an Open Access article distributed under the terms of the Creative Commons Attribution-NonCommercial-NoDerivatives License (http://creativecommons.org/licenses/by-nc-nd/4.0/), which permits non-commercial re-use, distribution, and reproduction in any medium, provided the original work is properly cited, and is not altered, transformed, or built upon in any way. 
Oracy skills is a term used widely in the literature in school settings (Gaunt and Stott 2018), and is an emerging concept in the higher education (HE) literature (Dippold et al. 2019; Heron 2019). There is little agreement on the terms used to define oracy skills (for example, communication skills, academic speaking skills), a lack of consensus on what oracy skills involve and thus scant recognition of how to teach and assess such skills (Dunbar, Brooks and Kubicka-Miller 2006; Robles 2012).

For students, academic speaking activities may be fraught with tensions due to misunderstanding participation procedures (Engin 2017), lack of explicit expectations from disciplinary tutors and a divergence of expectations around oracy skills necessary for successful classroom participation (Mack 2012). Whilst a number of studies have explored tutor perspectives, student voices in understanding oracy needs have been largely absent from the literature. This paper illuminates tutor and student expectations of oracy skills to identify convergences and divergences of perspectives with a view to establishing key oracy skills required for access to the learning conversations and the development of disciplinary understanding.

In this paper we use the term oracy skills to highlight a range of academic speaking skills. We argue that there is a need to establish a shared discourse to talk about oracy (Compton 2010) which includes explicit metalanguage identifying the dimensions of oracy. The Oracy Skills Framework, developed by Mercer, Warwick and Ahmed (2017) sits at the centre of this study (see Table 1). The Oracy Skills Framework was chosen as a heuristic as it represents a range of oracy skills that students might need to draw upon and was rigorously trialed and tested during the design phase (Mercer, Warwick and Ahmed 2017).

\section{Background}

\section{Oracy skills}

Academic speaking permeates all aspects of disciplinary practice and shapes and is shaped by the expectations of both the discipline and the academics (Neumann 2001). In the

Table 1. The oracy skills framework (Mercer, Warwick and Ahmed 2017).

\begin{tabular}{ll}
\hline Generic oracy skills & \multicolumn{1}{c}{ Specific oracy skills } \\
\hline Physical & - Fluency and pace of speech, tonal variation, clarity of \\
- Voice & pronunciation, voice projection \\
- Body language & Gesture and posture \\
\hline Linguistic & - Appropriate vocabulary choice \\
- Vocabulary & - Register, grammar \\
- Language variety & - Structure and organisation of talk \\
- Structure & Metaphor, humour irony, mimicry \\
\hline Cognitive & - Choice of content, building on the views of others \\
- Content & - Seeking information and clarification through questions, \\
- Slarifying and summarising & summarising \\
- Reasoning & - Maintaining focus on task, time-management \\
- Audience awareness & - Tiving reasons to support views, critically examining ideas \\
\hline Social and emotional & Taking into account level of audience \\
- Working with others & - Guiding or managing the interactions, turn-taking \\
- Listening and responding & - Sistening actively and responding appropriately \\
- Confidence in speaking & Self-assurance, liveliness and flair \\
\hline
\end{tabular}


same way that academic writing must conform to certain academic conventions, so must academic speaking both for formal spoken discourse events such as seminar discussions, presentations, question and answer sessions, but also informal spoken discourse events inside and outside the classroom. Spoken skills are key to accessing academic discourse (Mauranen 2012) and to socialising students into new disciplinary discourses.

Despite the growing body of research on oracy skills in compulsory school settings (Mercer and Dawes 2014; Mercer 2000; Vaish 2013), oracy is still a relatively underexplored area of study in $\mathrm{HE}$. This is surprising given the interactive nature of teaching and learning and the importance of academic speaking skills to academic achievement (Berman and Cheng 2001). Furthermore, whilst the development of literacy skills is gaining traction (Baker et al. 2019; Hathaway 2015), oracy skills are generally neglected.

Oracy skills have been framed in a number of ways and the two perspectives we explore here are oracy as competence and oracy for learning. Oracy as competence is viewed as a discrete subject to be taught and oracy for learning as a vehicle for communication and constructing understanding (Maclure 1988). In a higher education context, oracy as competence would typically be taught by language experts as part of an EAP programme (Mah 2016), and oracy for learning would be part of disciplinary studies in which students use language (in this case English) to share ideas.

Whilst it could be argued that a focus on oracy as competence gives value to studying oracy explicitly, it does leave oracy as a thinking tool neglected. A lack of recognition of oracy as a vehicle for learning, negotiating and thinking critically may have unintended consequences on attainment. The fundamental premise of the literature and thinking on oracy is a sociocultural perspective on learning, which posits that language (through talk) is a tool for thinking and for constructing understanding (Mercer 2000; Vygotsky 1986). As Barnes states, classroom talk between tutor and students, and talk amongst students 'has the power to shape knowledge through participant engagement with a range of processes: hypothesising, exploration, debate and synthesis' (Barnes 2010, p. 7). In this sense, language is not the object to be studied, but as a means of communicating and expressing ideas. In many institutions in both Anglophone and non-Anglophone contexts, the structure of support for non-native English speaking students is generally a 'silo' one, where they spend time in a pre-sessional course learning English as a subject (oracy as competence), with a focus on academic English (de Chazal 2014), and their disciplinary studies where they are expected to use language to learn (oracy for learning). As a result, there is a disjoint between the level of importance students give to different dimensions of the oracy framework.

\section{Tutor and student perspectives on oracy skills}

In the literature it has been noted that tutors voice concerns about students' linguistic proficiency (including oracy skills) for studying in an EMI context (Macaro et al. 2018) and their own role in supporting students' language development. In general, there seems to be a reluctance to support students' language skills or accept responsibility for developing language skills (Dearden 2014; Dearden and Macaro 2016). Furthermore, there seems to be considerable variation in levels of tutor awareness of both students' linguistic challenges and how to support them (Jenkins et al. 2019). 
A key theme in the literature on students' experiences of EMI has been the challenges they face in studying their discipline in a second language (L2). In the UAE context, Belhiah and Elhami (2015) note that students struggle to learn their discipline due to low language proficiency. Studies conducted in the Turkish context both by Kiliç (2018) and Kahvecioğlu (2019) found that students mostly feel the English language preparation prior to their studies did not prepare them for the challenges of studying a discipline in English. In one study, Jenkins et al. (2019) report that students believed that studying in English was good for future work, but they also thought that the L2 was a barrier to learning and they were concerned about the need to use 'correct' English. In terms of academic speaking specifically, a study of postgraduate students in Australia found that students worried about embarrassing themselves and lost confidence when they were not understood. Several students also commented that they did not like asking questions (Terraschke and Wahid 2011).

To summarise, students' access to the valuable learning classroom dialogue may be inhibited by their own linguistic challenges, a reluctance of tutors to support their language, a lack of awareness of both parties of the oracy skills required to participate in classroom dialogue and fundamentally a lack of shared terminology with which to discuss these expectations. Therefore, this study seeks to explore tutor and student expectations of and perspectives on oracy skills required for disciplinary study.

\section{Methodology}

This paper uses data from a larger study which explored the transition of pre-sessional students into their disciplinary studies in terms of their academic speaking skills (Dippold et al. 2020). This was a four-site study with Anglophone and non-Anglophone contexts: two HE institutions from the UK, one from Turkey and one from the United Arab Emirates. The study as a whole used a mixed-methods approach, with questionnaires and interviews. The design of the questionnaire was based on the Oracy Skills Framework (Mercer, Warwick and Ahmed 2017) and so for that reason in this paper we report only on the questionnaire data.

The research questions we asked were:

Research question 1: What are tutor and student expectations of oracy skills in disciplinary studies?

Research question 2: Do tutors and students view oracy as oracy as competence or oracy for learning?

\section{Participants}

Student participants in the larger study were undergraduate and postgraduate L2 English speaking students who had all studied in a pre-sessional programme and had transitioned into their disciplinary studies. The language teachers and disciplinary tutors were from all four institutions and were both L1 English speaking and L2 English speaking. Since the focus of the current paper is students' disciplinary studies, data is drawn from disciplinary tutors and students only. Table 2 below summarises the numbers from each site. 
Table 2. Summary of participants.

\begin{tabular}{lccc}
\hline Institutions & Students & Disciplinary tutors & Total \\
\hline UK HEI A & 10 & 55 & 65 \\
UK HEl B & 39 & 36 & 75 \\
HEI Turkey & 23 & 21 & 44 \\
HEI United Arab Emirates & 93 & 25 & 118 \\
\hline Total & 165 & 137 & 302 \\
\hline
\end{tabular}

Students participating in this study hailed from a range of academic disciplines, with 18.4\% indicating Arts and Humanities, 19.4\% STEM and 22.4\% Social Sciences. A large percentage of students categorised themselves under 'other' (39.4\%), which may have stemmed from a lack of understanding of how their subject is represented in the disciplinary groupings. As can be seen from the table, the student response rate in the UAE was very high, mainly as a result of encouragement from the Head of School. Ethical approval was granted by all four institutions and participants were provided with information sheets. All gave informed consent at the time of completing the questionnaire. The authors of this paper are either disciplinary or English language teachers in those institutions. This status allowed access to the participants and ensured there were no gate-keeping constraints. Furthermore, an insider perspective allowed the researchers to utilise their 'resources' (Holliday 2016) such as contextual and background information to analyse the data. However, to avoid bias, we have shown our 'workings' (Holliday 2016) through a description of the methods and analytical procedures.

\section{Materials}

Currently, there are no validated scales for the Oracy Skills Framework. For the purpose of this study an inventory was created with scales being informed by and representing the Oracy Skills Framework domains. To make the terms more accessible to all participants, the domains were renamed in the questionnaire:

Physical $==>$ Delivery skills

Linguistic $==>$ Language skills

Cognitive $==>$ Organising ideas

Social and emotional $==>$ Social skills

The questionnaire comprised closed and open questions providing both quantitative and qualitative data. The closed questions were based on the Oracy Skills Framework and aimed to elicit the level of importance given for each of the domains. The open questions are presented in Table 3 below and the closed questions are provided in Appendix A.

\section{Analysis: quantitative data}

Before analysing the quantitative data further, we validated the inventory for the four scales to ensure they represented the Oracy Skills Framework. Items were created for the four domains: Delivery Skills (2 items); Language Skills (4 items); Organising Ideas (6 items) and Social Skills (3 items) (see Table 1). Although this paper is not concerned with language teachers, their data were used to validate the scale. The scale used was from 'not important' to 'very important' and was coded 1-5. Principal component analysis (PCA) with varimax 
rotation was performed to determine the validity of the items in each scale (1) for students and (2) for tutors and language teachers together. A cut-off of 0.5 was used to determine the items that loaded on each factor (Salkind 2010). For both PCAs, the items loaded on four factors that corresponded to the four scales of the Oracy Skills Framework. Although not the purpose of our study, this analysis showed that the Oracy Skills Framework could be represented in a quantitative format.

The item 'Organisation of talk' did not load above 0.5 on Language Skills for the PCA on tutors and language teachers. As the factors were similar, the data for students, tutors and language teachers were pooled together and a PCA was performed. The item 'Organisation of talk' also did not have a loading above 0.5 , and hence was deleted from the Language Skills scale (see Table 3 ). This PCA accounted for $64 \%$ of the variance in the responses.

The Cronbach alpha was tested to determine the internal consistency for all the scales based on the items that loaded above 0.5 in Table 4 . The alphas were all satisfactory levels above 0.7 (Lavrakas 2008).

\section{Analysis: qualitative data}

The qualitative comments within the surveys were analysed using thematic analysis based on a priori codes. This deductive approach utilises a codebook or template which is based on the research questions and theoretical framework (Fereday and Muir-Cochrane 2006).

Table 3. Student and tutor open questions.

\begin{tabular}{|c|c|}
\hline Student open questions & Tutor open questions \\
\hline $\begin{array}{l}\text { - Are there any other speaking skills you need to be effec- } \\
\text { tive in your degree studies? Please explain. } \\
\text { - Please add any further comments on your use of spoken } \\
\text { academic English during your degree studies. }\end{array}$ & $\begin{array}{l}\text { - What informs your practice in planning your teaching } \\
\text { and supporting students in using English in spoken aca- } \\
\text { demic activities? } \\
\text { - Please note any further comments on your students' use } \\
\text { of spoken academic English }\end{array}$ \\
\hline
\end{tabular}

Table 4. Principal component analysis confirming the four scales from the Oracy Skills Framework with pooled data from students, tutors and language teachers.

\begin{tabular}{|c|c|c|c|c|c|}
\hline & \multicolumn{4}{|c|}{ Component } & \multirow[t]{2}{*}{ Cronbach Alpha } \\
\hline & 1 & 2 & 3 & 4 & \\
\hline $\begin{array}{l}\text { Delivery Skills } \\
\text { Volume of voice } \\
\text { Body language } \\
\end{array}$ & $\begin{array}{l}.183 \\
.093 \\
\end{array}$ & $\begin{array}{l}.174 \\
.158 \\
\end{array}$ & $\begin{array}{l}.071 \\
.224 \\
\end{array}$ & $\begin{array}{l}.839 \\
.851 \\
\end{array}$ & 0.76 \\
\hline $\begin{array}{l}\text { Language Skills } \\
\text { Correct vocabulary } \\
\text { Correct pronunciation } \\
\text { Correct grammar } \\
\text { Organisation of talk (deleted item) }\end{array}$ & $\begin{array}{l}.342 \\
.046 \\
.148 \\
.377\end{array}$ & $\begin{array}{l}.753 \\
.768 \\
.858 \\
.458\end{array}$ & $\begin{array}{l}-.022 \\
.134 \\
.089 \\
.138\end{array}$ & $\begin{array}{l}.058 \\
.333 \\
.037 \\
.400\end{array}$ & 0.80 \\
\hline $\begin{array}{l}\text { Organising Ideas } \\
\text { Using own ideas } \\
\text { Referring to others'ideas } \\
\text { Asking questions } \\
\text { Managing time } \\
\text { Justifying and supporting ideas } \\
\text { Awareness of other speakers }\end{array}$ & $\begin{array}{l}.720 \\
.779 \\
.613 \\
.535 \\
.747 \\
.553\end{array}$ & $\begin{array}{l}.197 \\
.005 \\
.112 \\
.273 \\
.128 \\
.114\end{array}$ & $\begin{array}{l}.031 \\
.077 \\
.193 \\
.203 \\
.175 \\
.448\end{array}$ & $\begin{array}{l}.139 \\
.036 \\
.143 \\
.170 \\
-.016 \\
.187\end{array}$ & 0.81 \\
\hline $\begin{array}{l}\text { Social Skills } \\
\text { Working with others } \\
\text { Listening and responding } \\
\text { Confidence }\end{array}$ & $\begin{array}{c}.239 \\
.256 \\
-.019\end{array}$ & $\begin{array}{l}-.005 \\
.130 \\
.478\end{array}$ & $\begin{array}{l}.807 \\
.836 \\
.505\end{array}$ & $\begin{array}{l}.133 \\
.077 \\
.268\end{array}$ & 0.70 \\
\hline
\end{tabular}


In this study, the research questions focus on oracy skills and our theoretical framework is the Oracy Skills Framework with its four dimensions: physical, linguistic, cognitive and socio-emotional. An iterative process of reading and re-reading the qualitative data guided the analysis with the researchers matching the codes with sections of data (Fereday and Muir-Cochrane 2006). The data were organised and stored in Nvivo.

\section{Findings}

In this section we present the findings from the quantitative data supported by the qualitative data. The research was concerned with how tutors and students perceive the importance of oracy skills at two levels: the group of skills represented by the Oracy Skills Framework domains and the individual skills represented by each individual item. Hence, the analysis did not take into account the country location of the participants. A series of one-way analysis of variance (ANOVA) tests with one between subject were used to test the difference in the means of the scales and items between tutors and students (see Table 5).

As can be seen from Table 5 there is divergence on what students and tutors think are important oracy skills. For example, students gave greater value to delivery skills (4.1 vs. 3.6) and language skills (4.2 vs. 3.8), whereas tutors gave greater value to organising ideas (4.3 vs. 4.1). In terms of social skills, students believed they were marginally more important ( 4.3 vs. 4.2 respectively) than tutors believed them to be.

In the section below we discuss the findings with reference to the four oracy skills domains using the original terms from the Oracy Skills Framework. The qualitative data is coded as following: T-Tutor comment, S-Student comment, Institution A,B,C and D.

\section{Physical dimension}

Body language as a feature of delivery skills was seen as more important by students than by tutors (4.1 vs. 3.4). This is reflected in the qualitative comments by students. Two students mentioned the importance of a loud voice, and the two references to body language by students highlighted eye contact as important:

(1) The eye contact is very important while you do presentation. (SB)

(2) Body language is very important and eye contact.(SB)

Although the questionnaire did not include fluency as an option for Delivery skills, according to the detailed description of the oracy skills domains fluency is a feature of voice. Interestingly, there were several references to fluency from students and tutors. One student noted that fluency was an important spoken skill in (3) whilst a tutor demonstrated their expectations for fluency rather than accuracy in (4). This requirement of communication and fluency over accurate language use was a theme reflected in other domains.

(3) When I talk with others in English, l am nervous that l can't speak fluently. (SD)

(4) I do not expect non-native English speakers to be perfect at English, far from it, but I do expect that we will be able to converse relatively fluidly in taught settings. (TA) 
Table 5. Means and standard deviations of the four scales and their related items for the tutors and students.

\begin{tabular}{|c|c|c|c|c|c|}
\hline & $\begin{array}{l}\text { Student } \\
(n=165)\end{array}$ & SD & $\begin{array}{c}\text { Tutor } \\
(n=137)\end{array}$ & SD & $\eta^{2}$ \\
\hline Delivery Skills*** & 4.1 & 0.87 & 3.6 & 0.94 & 0.07 \\
\hline Volume of voice* & 4.1 & 0.97 & 3.9 & 0.91 & 0.12 \\
\hline Body language $^{* * *}$ & 4.1 & 0.99 & 3.4 & 1.18 & 0.10 \\
\hline Language Skills ${ }^{* *}$ & 4.2 & 0.77 & 3.8 & 0.82 & 0.07 \\
\hline Correct vocabulary & 4.3 & 0.85 & 4.2 & 0.90 & 0.01 \\
\hline Correct pronunciation ${ }^{* *}$ & 4.3 & 0.83 & 3.5 & 0.99 & 0.14 \\
\hline Correct grammar** & 4.1 & 0.99 & 3.7 & 1.00 & 0.05 \\
\hline Organisation of talk (deleted item) & 4.4 & 0.79 & 4.3 & 0.81 & 0.00 \\
\hline Organising Ideas** & 4.1 & 0.68 & 4.3 & 0.53 & 0.02 \\
\hline Using own ideas* & 4.1 & 0.90 & 4.4 & 0.73 & 0.02 \\
\hline Referring to others' ideas** & 3.9 & 1.01 & 4.3 & 0.82 & 0.05 \\
\hline Asking questions** & 3.9 & 0.99 & 4.3 & 0.77 & 0.04 \\
\hline Managing time & 4.2 & 0.88 & 4.2 & 0.75 & 0.00 \\
\hline Justifying and supporting ideas* & 4.3 & 0.76 & 4.5 & 0.74 & 0.01 \\
\hline Awareness of other speakers & 4.0 & 1.00 & 4.0 & 0.95 & 0.00 \\
\hline Social Skills ${ }^{+}$ & 4.3 & 0.75 & 4.2 & 0.63 & 0.01 \\
\hline Working with others & 4.0 & 1.10 & 4.2 & 0.91 & 0.00 \\
\hline Listening and responding & 4.3 & 0.88 & 4.4 & 0.71 & 0.00 \\
\hline Confidence** & 4.5 & 0.74 & 3.9 & 0.90 & 0.12 \\
\hline
\end{tabular}

\section{Linguistic dimension}

Expectations of students' oracy skills are to a large extent defined and shaped by the disciplinary discourse and expectations. Unsurprisingly, knowledge of disciplinary terminology was seen as key to participating in the discourse community. Both tutors and students were aware of the importance of vocabulary in the quantitative data (4.3 and 4.2, respectively). This expectation was also reflected in the qualitative comments.

For example, the student in (5) below uses the phrase 'technical terms' to refer to disciplinary terminology, and highlights the difficulty of translating from L1 to L2.

(5) Some technical terms are firstly learned in native languages and it makes the communications more difficult and time-consuming (SD)

In (6) below, the student uses a more generic term 'words' to describe vocabulary, but nevertheless they highlight the link between the vocabulary and fluency:

(6) I have to improve my words because it hard for me to word [sic] come out clearly (SA)

There was agreement over the importance of accuracy and appropriacy of disciplinary vocabulary. The tutor in (7) below highlights the relationship between using appropriate terminology, the genre of scientific communication and demonstrating understanding of knowledge.

(7) I found myself very disappointed by the lack of vocabulary and the poor capacity of expression of a significant group of the students; they would use informal expressions to describe their experimental work and results, which are not appropriate for scientific communication. (TA)

Disciplinary terminology is not part of a student's linguistic repertoire regardless of first language and therefore needs to be explicitly addressed by the tutors. In (8) below, the tutor acknowledges that disciplinary terminology requires focused and explicit instruction: 
(8) Terminology is highly important, but this is never assumed and something that has to be taught. (TD)

Accuracy and appropriacy of pronunciation and grammar were viewed differently by students and tutors. As the quantitative data demonstrates, students gave greater value to accuracy of pronunciation (4.3 vs. 3.5$)$ and accuracy of grammar (4.1 vs. 3.7). The qualitative data reflected tensions in the differences in perspectives. One tutor in (9) talks of how students' desire for accuracy must not compromise their willingness to use English in class and they explain how they actively encourage mistakes to support willingness to communicate.

(9) I insist that they speak English. I tell them that I would rather they make 1000 mistakes in English than speak perfect Turkish. (TC)

Arguably, in a non-Anglophone context where the majority of students and tutors share an L1 and share similar L2 learning experiences, importance of accuracy in an L2 is part of the educational culture.

\section{Cognitive dimension}

The cognitive dimension reflects skills necessary for intellectual engagement in a HE context. For example, seminars are opportunities for students to make their learning visible through the talk (Mercer 2000) by engaging in discussion and debate. In all skills but managing time and awareness of other speakers, tutors afforded a higher importance. For example, tutors gave greater value to referring to others' ideas (4.3 vs. 3.9). Similarly, asking questions was seen as more important for tutors than for students (4.3 vs. 3.9). This was reflected in the qualitative data. In (10) below, the tutor views questions as an opportunity for checking of learning:

(10) They don't have to speak in class but if, for e.g., they don't ask questions for clarification I won't know that they haven't understood something. (TB)

As well as checking understanding, questions are also part of critical thinking and therefore crucial to intellectual debate and critique. The expectation from the tutor below is for a very particular type of question, which is open to debate in itself. Nevertheless, the comment (11) confirms the importance in disciplinary studies of asking questions.

(11) Need to improve ability for critical discussion, creative language, reflection and useful, effective, efficient questions. (TA)

Confidence is key to the ability to ask the types of questions described by the tutor in (12). The tutor recognises this, confirming the close relationship between the oracy dimensions of social and emotional, and cognitive (Dippold et al. 2019):

(12) [The] biggest issue regardless of first language is confidence to ask questions in class (B)

The data revealed a wide range of practices by disciplinary tutors with some explicitly describing how they support students in developing these skills. However, as is seen below, good practice often extends merely again to 'encouraging' or providing opportunities, without an understanding that guided intervention and input is also necessary. 
(13) [I] encourage students to ask questions, engage with ideas (and properly reference them, which can be an issue), and feel free to challenge and develop original thinking. (TB)

The quantitative data demonstrates the lack of importance and awareness that students give to cognitive skills. This is again reflected in the paucity of qualitative student data relating to this dimension. The student comment in (14) focuses on the cognitive skills of criticizing and argumentation as important in academic speaking.

(14) Explanations and arguments are important when you are discussing with others in order to achieve an agreement. (SD)

\section{Social and emotional dimension}

Students highlighted the importance of confidence as a dimension of oracy skills and its role in developing oracy skills cannot be denied. The quantitative data revealed some differences in perspectives. Students gave confidence high importance ( 4.5 vs. 3.9). This is borne out in the qualitative data. For example, in the following comments, all students demonstrate the foundational role of confidence in academic speaking. In (15) the student views confidence as taking priority over accuracy and the comment (16) reveals the relationship between confidence and success.

(15) Be confident when talking even though there are mistakes (SB)

(16) Confidence is what most students who are not doing well at English lack of [sic] (SD)

\section{Discussion}

In this section we answer the research questions posed at the beginning of the paper. We draw on the quantitative analysis of the Oracy Skills Framework scales that we created and validated and the relevant literature to explore the different perspectives and expectations of oracy skills in disciplinary studies.

\section{Research question 1: what are tutor and student expectations of oracy skills in disciplinary studies?}

Based on the Oracy Skills Framework scales, it appears that tutors and students vary in their expectations of oracy skills in higher education with mostly divergent values, converging only on the importance of disciplinary terminology and confidence. With reference to the Oracy Skills Framework, as seen in the quantitative data, and reflected in the qualitative comments, tutors appear to value the cognitive dimension over the other dimensions, whereas students seem to place greater importance on linguistic and social and emotional dimensions. This divergence is problematic for a number of reasons. Students will focus on accuracy over fluency, and will pay less attention to oracy skills which reflect key purposes of higher education - argumentation, questioning, justification and clarifying ideas. As a result, students may be unable to demonstrate disciplinary understanding, and the tutors will be unable to check understanding. The tension between oracy as competence and oracy for learning is reflected in these divergent views. 
Whilst these results may not be unsurprising in the context of anecdotal examples and experiences, the data does provide empirical evidence for why students may not feel supported in their disciplinary studies, why their academic speaking activities in their disciplinary studies bears little resemblance to their language preparation studies (Dippold 2015), and why tutors mistake silence for lack of understanding. Tutors are focused on supporting the construction of students' disciplinary knowledge, and therefore value cognitive skills which demonstrate this disciplinary understanding. Asking questions, reasoning, critical thinking and debate are expectations whilst linguistic accuracy is seen as unimportant. The language used to describe oracy or speaking reveals a non-systematic approach and underpins a lack of shared understanding amongst tutors. Therefore, we argue for the use of the Oracy Skills Framework as a tool which can provide a shared terminology for tutors and students, and which emphasises the range of skills which comprise oracy. Tutors' views would be opened up to the linguistic domain and its key role in the pre-sessional courses, and perhaps better understand students' reliance on these linguistic skills. Similarly, students would strive to develop oracy skills in the cognitive domain, including argumentation and critical thinking, skills valorized by tutors.

\section{Research question 2: do tutors and students view oracy as oracy as competence or oracy for learning?}

The data reflects differing perspectives on oracy. An oracy as competence perspective, in which a language focus prevails, is part of the language preparation experience of students. It is seen in student comments reflecting the importance of accuracy, but also in tutor comments relating to the importance of disciplinary terminology. We argue that linguistic skills such as vocabulary are key to disciplinary understanding and the critical thinking required in a particular discipline (Bruce 2020), and could be considered key 'pinch points' for student success and achievement (Dippold et al. 2019). Oracy for learning is the prevailing perspective of tutors given the importance they ascribe to the cognitive domain of oracy skills. However, there is an assumption that students already possess the pre-requisite skills to be able to participate confidently and persuasively in the classroom discourse. We argue that tutors need to recognise that all students, regardless of linguistic background, need explicit teaching of oracy skills (Doherty et al. 2011; Heron 2019) to support their classroom participation, but suggestions that tutors embed what is seen as language support into their teaching is met with resistance (Dearden and Macaro 2016). The myth that the discipline tutor cannot and should not be a language teacher needs to be debunked.

\section{How can we enhance students" opportunities for participation?}

In this section we outline a number of practical suggestions for tutors and students informed by these findings, all of which have the aim of enhancing students' opportunities for participation. We also draw on our own experiences of working with ESL students as language specialists and disciplinary tutors. What is noteworthy is that the suggestions below will support all students regardless of linguistic background (Dippold et al. 2019).

Firstly, we believe that it is important for students and tutors to use a shared metalanguage in describing oracy skills (see Heron 2019). This can be achieved through reference to the Oracy Skills Framework in relevant module documentation such as grade descriptors and 
assessment rubrics. Teaching and assessment strategies need to address and rehearse these strategies explicitly through classroom activities. A shared metalanguage to talk about language is key to understanding student needs and cannot be underestimated (Compton 2010; Heron 2019). The data revealed a myriad of ways in which tutors articulated their expectations of oracy skills, for example using phrases such 'a certain level of English' and 'a minimum expected standard of English'. Tutors need a shared metalanguage to recognise the different dimensions of oracy and to be able to support students in their development of these skills in an embedded pedagogic approach. However, in the same way that academic writing genres are framed by the discipline (Hyland 2008), so are academic speaking genres and we accept that there will be disciplinary differences in expectations (Hyland 2011). Yet the Oracy Skills Framework is based on a generalised understanding of oracy which allows nuanced and disciplinary adaptations and tutors can draw on different skills depending on the purpose, register and genre of the speaking event (Mercer, Warwick and Ahmed 2017).

In this context, it is particularly important to upskill teachers. As Baker (2019) points out, we cannot expect tutors to be aware of students needs if they have not been exposed to these ideas. Awareness of the dimensions of oracy, and of the importance of oracy and academic speaking for learning and teaching in the classroom can be integrated into teacher training opportunities such as the PGCertHE in the UK. At the moment, such teacher training programmes do not provide any such opportunities in a systematic manner.

And finally, we argue that positioning oracy skills within the wider frame of academic literacies (Lillis and Scott 2007) would remove the burden of responsibility for 'appropriacy and correctness' from international students and counteract the deficit discourse through which international students' language skills are frequently being described. It would instead embed oracy in disciplinary practice, alongside writing (Hathaway 2015; Wingate, Andon, and Cogo 2011) and reading (Baker et al. 2019; Clarence and Bharuthram 2015). It would also turn the development of oracy skills into an endeavor shared by home and international students, rather than 'oracy skills' being bolted onto the curriculum exclusively for non-native speakers in the form of EAP support classes.

\section{Recommendations for practice}

In this section we outline a number of recommendations with respect to the Oracy Skills Framework.

\section{Physical dimension}

It is important that tutors value the importance of body language as perceived by students. Appropriate body language can have a significant impact on confidence, and as has been seen, confidence underpins many of the other oracy skills.

\section{Linguistic dimension}

The literature suggests that understanding and use of key disciplinary terminology is crucial to accessing disciplinary content (Basturkmen 2018) and the data revealed that there was agreement between students and tutors on the importance of vocabulary. These shared expectations can be leveraged. For example, providing terminology lists before classes can guide students, and tutors can highlight key terms as they appear in teaching sessions. 


\section{Cognitive dimension}

There needs to be a focus on developing students' questioning skills. These skills are key to accessing disciplinary content, developing understanding and providing tutors with feedback. Questioning should feature as part of the language preparation prior to the subject classes (in pre-sessional) but to underscore the embedded nature of oracy skills development we suggest tutors have explicit conversations with students about the importance and purpose of questioning.

\section{Social and emotional dimension}

Establishing a supportive environment is key. Alexander's (2004) model of dialogic teaching approach underlines a supportive environment in which there is no fear of embarrassment and where students feel safe to share ideas. Confidence is a fluid concept (Gravett 2020) and co-constructed in spoken discourse so all participants need to be mindful of its contingency on tutor and student feedback.

\section{Conclusion}

This study sought to explore tutor and student expectations of oracy skills in disciplinary studies and whether they view oracy as competence or oracy for learning. Despite the centrality of classroom dialogue to developing key disciplinary terminology and concepts, scant attention has been paid to oracy skills in the higher education research, pedagogic and teacher education literature. The findings have identified a divergence of tutor and student expectations of oracy skills, highlighting the need for explicit discussion of what disciplinary academic speaking involves, and what language skills students require to be able to participate in classroom dialogue. The findings have also raised important questions about tutor practices in supporting ESL students, and the language they use to describe these key oracy skills. Provision of a common reference point to describe, and therefore teach and assess oracy skills can contribute to a shared understanding between tutors and students. The Oracy Skills Framework has been extensively used in compulsory school settings and there is a strong indication from this study that the same tool could be a significant contribution to higher education pedagogy.

This study involved participants from a number of different linguistic, disciplinary and cultural contexts. Whilst we found broad commonalities across the contexts, we acknowledge that there may be variation in perceptions amongst participants and further research might explore these differences.

\section{Disclosure statement}

No potential conflict of interest was reported by the author(s).

\section{Funding}

This work was supported by the British Council under the English Language Teaching Research Awards 2018-2019. 


\section{ORCID}

Marion Heron (D) http://orcid.org/0000-0002-6129-1265

Doris Dippold (D http://orcid.org/0000-0001-6193-4710

Anesa Hosein (D http://orcid.org/0000-0002-7325-5640

Tijen Aksit ID http://orcid.org/0000-0001-6154-3656

Necmi Aksit (D http://orcid.org/0000-0003-1382-6664

Jill Doubleday (D) http://orcid.org/0000-0002-9036-9973

Kara McKeown (DD http://orcid.org/0000-0003-3658-8873

\section{References}

Alexander, R. 2004. Dialogic Teaching. York: Dialogos.

Arkoudis, S., and L. Doughney. 2014. "Good Practice Report-English Language Proficiency." Sydney: Office for Learning and Teaching. https://melbourne-cshe.unimelb.edu.au/_data/assets/pdf_file/0004/1489162/GPR_English_language_2014.pdf.

Baker, S., B. Bangeni, R. Burke, and A. Hunma. 2019. "The Invisibility of Academic Reading as Social Practice and Its Implications for Equity in Higher Education: A Scoping Study." Higher Education Research \& Development 38 (1): 142-156. doi:10.1080/07294360.2018.1540554.

Barnes, D. 2010. "Why Talk is Important." English Teaching 9 (2): 7-10.

Basturkmen, H. 2018. "Dealing with Language Issues during Subject Teaching in EMI: The Perspectives of Two Accounting Lecturers." TESOL Quarterly 52 (3): 692-700. doi:10.1002/tesq.460.

Belhiah, H., and M. Elhami. 2015. "English as a Medium of Instruction in the Gulf: When Students and Teachers Speak." Language Policy 14 (1): 3-23. doi:10.1007/s10993-014-9336-9.

Berman, R., and L. Cheng. 2001. "English Academic Language Skills: Perceived Difficulties by Undergraduate and Graduate Students, and Their Academic Achievement." Canadian Journal of Applied Linguistics 4 (1): 25-40.

Bruce, I. 2020. Expressing Critical Thinking through Disciplinary Texts: Insights from Five Genre Studies. London: Bloomsbury Academic.

Clarence, S., and S. Bharuthram. 2015. "Teaching Academic Reading as a Disciplinary Knowledge Practice in Higher Education." South African Journal of Higher Education 29 (2): 42-55.

Compton, J. 2010. "Speaking of Speech with the Disciplines: Collaborative Discussions about Collaborative Speech." Arts and Humanities in Higher Education 9 (2): 243-255. doi:10.1177/ 1474022209359053.

Dearden, J. 2014. English as a Medium of Instruction-a Growing Global Phenomenon. British Council https://www.britishcouncil.es/sites/default/files/british_council_english_as_a_medium_of_instruction.pdf.

Dearden, J., and E. Macaro. 2016. "Higher Education Teachers' Attitudes towards English Medium Instruction: A Three-Country Comparison." Studies in Second Language Learning and Teaching 6 (3): 455-486. doi:10.14746/sllt.2016.6.3.5.

De Chazal, E. 2014. English for Academic Purposes-Oxford Handbooks for Language Teachers. Oxford: Oxford University Press.

Dippold, D. 2015. Classroom Interaction: The Internationalised Anglophone University. Basingstoke: Palgrave Macmillan UK.

Dippold, D., S. Bridges, S. Eccles, and E. Mullen. 2019. “Taking ELF off the Shelf: Developing HE Students' Speaking Skills through a Focus on English as a Lingua Franca." Linguistics and Education 54: 100761. doi:10.1016/j.linged.2019.100761.

Dippold, D., M. Heron, T. Akşit, N. Akşit, J. Doubleday, and K. McKeown. 2020. "ELT Research Papers." https://www.teachingenglish.org.uk/sites/teacheng/files/L017_ELTRA_FINAL.pdf.

Doherty, C., M. Kettle, L. May, and E. Caukill. 2011. “Talking the Talk: Oracy Demands in First Year University Assessment Tasks." Assessment in Education: Principles, Policy and Practice 18 (1): 27-39. doi:10.1080/0969594X.2010.498775. 
Dunbar, N. E., C. F. Brooks, and T. Kubicka-Miller. 2006. "Oral Communication Skills in Higher Education: Using a Performance-Based Evaluation Rubric to Assess Communication Skills." Innovative Higher Education 31 (2): 115-128. doi:10.1007/s10755-006-9012-x.

Engin, M. 2017. "Contributions and Silence in Academic Talk: Exploring Learner Experiences of Dialogic Interaction." Learning, Culture and Social Interaction 12: 78-86. doi:10.1016/j.lcsi. 2016.11.001.

Fereday, J., and E. Muir-Cochrane. 2006. "Demonstrating Rigor Using Thematic Analysis: A Hybrid Approach of Inductive and Deductive Coding and Theme Development." International Journal of Qualitative Methods 5 (1): 80-92. doi:10.1177/160940690600500107.

Gaunt, A., and A. Stott. 2018. Transform Teaching and Learning through Talk: The Oracy Imperative. Lanham, Maryland: Rowman \& Littlefield.

Gravett, K. 2020. "Feedback Literacies as Sociomaterial Practice." Critical Studies in Education: Advance online publication. doi:10.1080/17508487.2020.1747099.

Hathaway, J. 2015. "Developing That Voice: locating Academic Writing Tuition in the Mainstream of Higher Education.” Teaching in Higher Education 20 (5): 506-517. doi:10.1080/13562517.2015. 1026891.

Heron, M. 2019. "Making the Case for Oracy Skills in Higher Education: practices and Opportunities." Journal of University Teaching \& Learning Practice 16 (2): 9.

Holliday, A. 2016. Doing and Writing Qualitative Research. London: SAGE.

Hyland, K. 2008. "Genre and Academic Writing in the Disciplines." Language Teaching 41 (4): $543-$ 562. doi:10.1017/S0261444808005235.

Hyland, K. 2011. "10 Disciplines and Discourses: Social Interactions in the Construction of Knowledge." Perspectives on Writing 193: 226-260.

Jenkins, J., W. Baker, J. Doubleday, and Y. Wang. 2019. "How Much Linguistic Diversity on a UK University Campus?" In Linguistic Diversity on the EMI Campus: Insider Accounts of the Use of English and Other Languages in Universities within Asia, Australasia, and Europe, edited by J. Jenkins, and A. Mauranen. Oxon: Routledge.

Kahvecioğlu, A. S. 2019. "The Perceptions of the Main Stakeholders of Universities regarding EMI Instruction in Turkey." Unpublished.” master's thesis., Bilkent University, Ankara.

Kiliç, G. 2018. "Stakeholders' Perception of the Academic Writing Needs of EMI University Students and How These Needs Are Met: A Case Study." Unpublished.” master's thesis., Bilkent University, Ankara.

Lavrakas, P. J. 2008. Encyclopedia of Survey Research Methods (Vols. 1-0). Thousand Oaks, CA: SAGE Publications, Inc.

Lillis, T., and T. Scott. 2007. "Defining Academic Literacies Research: issues of Epistemology, Ideology and Strategy." Journal of Applied Linguistics 4 (1): 5-32.

Macaro, E., S. Curle, J. Pun, J. An, and J. Dearden. 2018. "A Systematic Review of English Medium Instruction in Higher Education." Language Teaching 51 (1): 36-76. doi:10.1017/ S0261444817000350.

Mack, L. 2012. "Does Every Student Have a Voice? Critical Action Research on Equitable Classroom Participation Practices." Language Teaching Research 16 (3): 417-434. doi:10.1177/ 1362168812436922.

Maclure, M. 1988. "Introduction: Oracy: Current Trends in Context." Oracy Matters: The Development of Talking and Listening in Education, edited by M. MacLure, T. Phillips and A. Wilkinson, 1-9. Milton Keynes: Open University Press.

Mah, A. S. H. 2016. "Oracy is as Important as Literacy: Interview with Christine CM Goh." RELC Journal 47 (3): 399-404. doi:10.1177/0033688216681671.

Mauranen, A. 2012. Exploring ELF: Academic English Shaped by Non-Native Speakers. Cambridge: Cambridge University Press.

Mercer, N. 2000. Words and Minds: How we Use Language to Think Together. Oxford: Routledge.

Mercer, N., and L. Dawes. 2014. "The Study of Talk between Teachers and Students, from the 1970s Until the 2010s." Oxford Review of Education 40 (4): 430-445. doi:10.1080/03054985.2014.934087. 
Mercer, N., P. Warwick, and A. Ahmed. 2017. “An Oracy Assessment Toolkit: Linking Research and Development in the Assessment of Students' Spoken Language Skills at Age 11-12." Learning and Instruction 48: 51-60. doi:10.1016/j.learninstruc.2016.10.005.

Neumann, R. 2001. "Disciplinary Differences and University Teaching." Studies in Higher Education 26 (2): 135-146. doi:10.1080/03075070120052071.

Robles, M. M. 2012. "Executive Perceptions of the Top 10 Soft Skills Needed in Today's Workplace." Business Communication Quarterly 75 (4): 453-465. doi:10.1177/1080569912460400.

Salkind, N. J. 2010. Encyclopedia of Research Design (Vols. 1-0). Thousand Oaks, CA: SAGE Publications, Inc.

Terraschke, A., and R. Wahid. 2011. "The Impact of EAP Study on the Academic Experiences of International Postgraduate Students in Australia." Journal of English for Academic Purposes 10 (3): 173-182. doi:10.1016/j.jeap.2011.05.003.

Vaish, V. 2013. "Questioning and Oracy in a Reading Program." Language and Education 27 (6): 526-541. doi:10.1080/09500782.2012.737334.

Vygotsky, L. S. 1986. Thought and Language. Cambridge, MA: MIT Press.

Wingate, U., N. Andon, and A. Cogo. 2011. "Embedding Academic Writing Instruction into Subject Teaching: A Case Study." Active Learning in Higher Education 12 (1): 69-81. doi:10.1177/ 1469787410387814.

\section{Appendix A}

Student and tutor closed questions

\begin{tabular}{|c|c|}
\hline $\begin{array}{l}\text { Student closed questions } \\
\begin{aligned} 1 & =\text { not important } \\
2 & =\text { slightly important } \\
3 & =\text { moderately important } \\
4 & =\text { important } \\
5 & =\text { very important }\end{aligned}\end{array}$ & $\begin{array}{l}\text { Tutor closed questions } \\
\begin{aligned} 1 & =\text { not important } \\
2 & =\text { slightly important } \\
3 & =\text { moderately important } \\
4 & =\text { important } \\
5 & =\text { very important }\end{aligned}\end{array}$ \\
\hline $\begin{array}{l}\text { PHYSICAL } \\
\text { How important are delivery skills for you to be effective } \\
\text { in your degree studies? } \\
\text { - Volume of voice } \\
\text { - Body language }\end{array}$ & $\begin{array}{l}\text { PHYSICAL } \\
\text { How important are delivery skills for students to be } \\
\text { effective in your modules / classes? } \\
\text { - Volume of voice } \\
\text { - Body language }\end{array}$ \\
\hline $\begin{array}{l}\text { LINGUISTIC } \\
\text { How important are language skills for you to be } \\
\text { effective in your degree studies? } \\
\text { - Correct vocabulary } \\
\text { - Correct pronunciation } \\
\text { - Correct grammar } \\
\text { - Organisation of talk }\end{array}$ & $\begin{array}{l}\text { LINGUISTIC } \\
\text { How important are language kills for students to be } \\
\text { effective in your modules / classes? } \\
\text { - Correct vocabulary } \\
\text { - Correct pronunciation } \\
\text { - Correct grammar } \\
\text { - Organisation of talk }\end{array}$ \\
\hline $\begin{array}{l}\text { COGNITIVE } \\
\text { How important are skills in organising ideas for you to } \\
\text { be effective in your degree studies? } \\
\text { - Using own ideas } \\
\text { - Referring to others' ideas } \\
\text { - Asking questions } \\
\text { - Managing time } \\
\text { - Justifying and supporting ideas } \\
\text { - Awareness of other speakers }\end{array}$ & $\begin{array}{l}\text { COGNITIVE } \\
\text { How important are skills in organising ideas for } \\
\text { students to be effective in your modules / classes? } \\
\text { - Using own ideas } \\
\text { - Referring to others' ideas } \\
\text { - Asking questions } \\
\text { - Managing time } \\
\text { - Justifying and supporting ideas } \\
\text { - Awareness of other speakers }\end{array}$ \\
\hline $\begin{array}{l}\text { SOCIAL AND EMOTIONAL } \\
\text { How important are social skills for you to be effective in } \\
\text { your degree classes? } \\
\text { - Working with others } \\
\text { - Listening and responding } \\
\text { - confidence }\end{array}$ & $\begin{array}{l}\text { SOCIAL AND EMOTIONAL } \\
\text { How important are social skills for students to be } \\
\text { effective in your modules / classes? } \\
\text { - Working with others } \\
\text { - Listening and responding } \\
\text { - Confidence }\end{array}$ \\
\hline
\end{tabular}

